OPEN ACCESS

Edited by:

Yun Dai,

Peking University First Hospital, China

Reviewed by:

Ali Coskun,

Izmir Bozyaka Eğitim ve Araştirma

Hastanesi, Turkey

Zilvinas Saladzinskas,

Lithuanian University of Health

Sciences, Lithuania

*Correspondence:

Zhaopeng Yan

yanzpus@outlook.com

TORCID:

Rui Wang

orcid.org/0000-0003-1728-1868

Zhaopeng Yan

orcid.org/0000-0003-1247-2067

Specialty section:

This article was submitted to

Gastrointestinal Cancers,

a section of the journal

Frontiers in Oncology

Received: 16 October 2019 Accepted: 25 November 2019

Published: 10 December 2019

Citation

Wang R and Yan Z (2019) Rectal Mucinous Adenocarcinoma Invading

Retrorectal Dermoid Cysts: A Case

Report. Front. Oncol. 9:1389.

doi: 10.3389/fonc.2019.01389

\section{Rectal Mucinous Adenocarcinoma Invading Retrorectal Dermoid Cysts: A Case Report}

\author{
Rui Wang ${ }^{1 \dagger}$ and Zhaopeng Yan ${ }^{2 * t}$ \\ ${ }^{1}$ Department of Critical Care Medicine, Shengjing Hospital, China Medical University, Shenyang, China, ${ }^{2}$ Department of \\ General Surgery, Shengjing Hospital, China Medical University, Shenyang, China
}

Rectal mucinous adenocarcinoma is a subtype of colorectal adenocarcinoma, which is more aggressive and prone to invade adjacent normal organs or tissues compared with non-mucinous adenocarcinoma. Retrorectal dermoid cyst is a rare congenital disease, which usually are benign but with a potential for malignant degeneration. In this article, we report a case which presented a rectal mucinous adenocarcinoma invading into retrorectal dermoid cysts, indicating that besides adjacent normal organs or tissues, malignancies can also invade adjacent tumors, making their diagnosis and management more complicated. In such cases, double primary tumors should be considered, and they should be removed surgically.

Keywords: rectal cancer, retrorectal cyst, tailgut cyst, developmental cyst, retrorectal space

\section{INTRODUCTION}

The incidence of colorectal cancer ranks third among all malignancies worldwide, and rectal adenocarcinoma is the most common malignant tumor of the rectum $(1,2)$. The clinical practice guidelines for treatment of rectal adenocarcinoma include European ESMO guidelines and American NCCN guidelines. Retrorectal tumors are heterogeneous, including tailgut cysts, teratomas, epidermoid cysts, and dermoid cysts (3). As these are rare tumors in clinical practice, there are no guidelines to follow in the management of retrorectal tumors. Here, we describe a 50 -year-old male patient, who presented with a rectal tumor complicated by retrorectal tumors. There was no clear border between the rectal tumor and the retrorectal tumors, and parts of the two tumors were fused together, which made the case difficult to diagnose and manage.

\section{CASE REPORT}

A 50-year-old previously healthy man presented to the emergency department with a 3-day history of worsening bloating, abdominal pain, and inability to pass flatus. The physician made a digital rectal examination and found a stricture of the rectum $2 \mathrm{~cm}$ above the anal edge. After depositing a tube into the proximal cavity of the narrowing part of the rectum, flatus and stool passed out, relieving the abdominal pain and bloating. A rectal MRI, an abdominal enhanced CT scan, and PET-CT were performed, finding that a rectal tumor growing circumferentially caused a stricture of the lower rectum. In the retrorectal space, several cysts were present, the largest of which had a diameter of about $8 \mathrm{~cm}$. These cysts had a clear border with the sacrum but showed adhesion to the rectal cancer (Figure 1). The patient recalled that, 3 months previously, he received a routine health checkup, but a colonoscopy found nothing abnormal. The rectal tumor was probably missed 

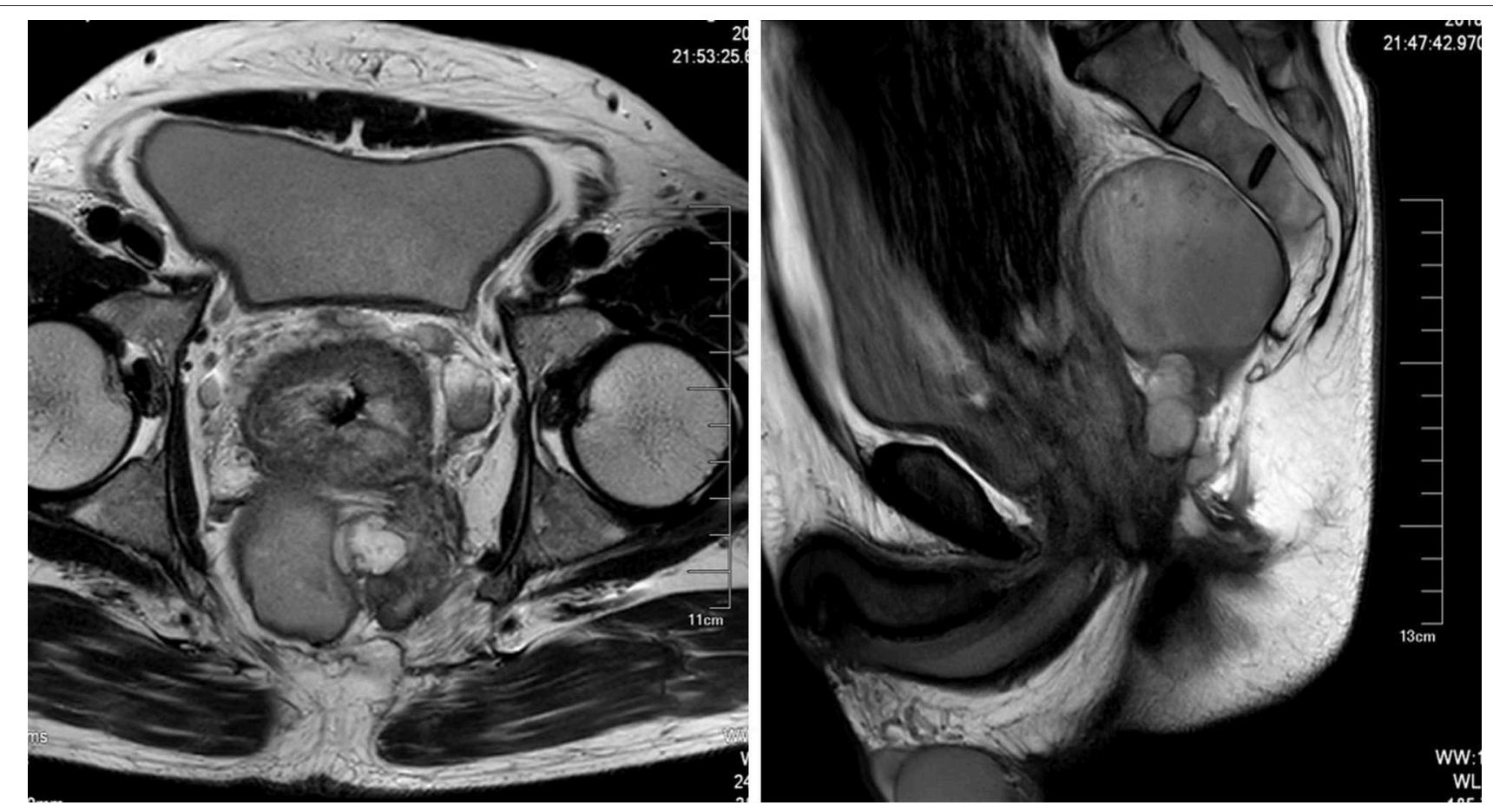

FIGURE 1 | MRI: Several cysts were located in the retrorectal space, which had a clear border with the sacrum but adhered to the rectal tumor.

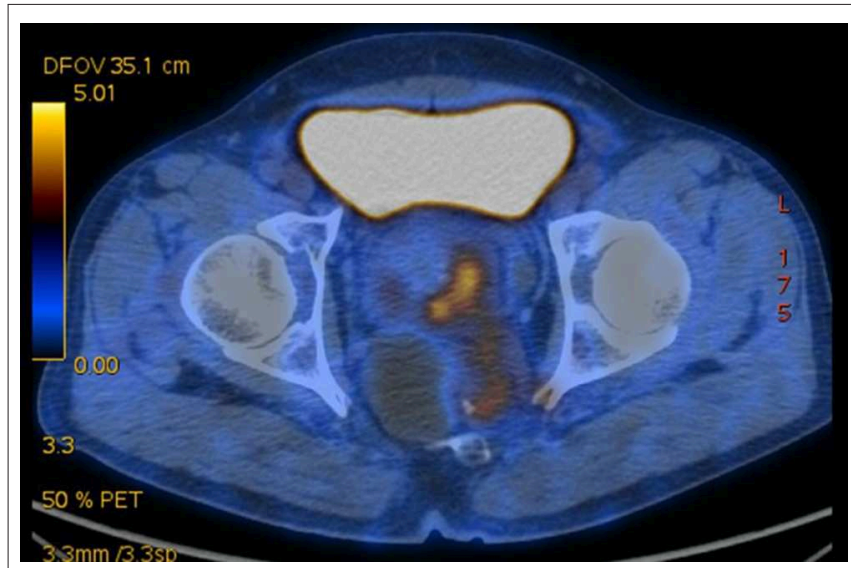

FIGURE 2 | PET-CT revealed that the rectal tumor had high FDG accumulation; the cysts did not.

due to its location adjacent to the anus. CT and PET-CT revealed that the lower part of the rectum was thickened, and that accumulation of fluorine-labeled fluorodeoxyglucose (FDG), a marker for the uptake of glucose, was enhanced with an SUVmax of 6.36, indicating a suspicious malignancy. FDG accumulation in the retrorectal cysts was not enhanced (Figure 2). As the bowel was obstructed, the present case was a surgical emergency, and there was no opportunity to conduct a biopsy. MRI, CT, and PET-CT images revealed that the rectal lesion and retrorectal lesions were anatomically close. It was not clear if the case should be considered as double-primary disorders or as a single rare

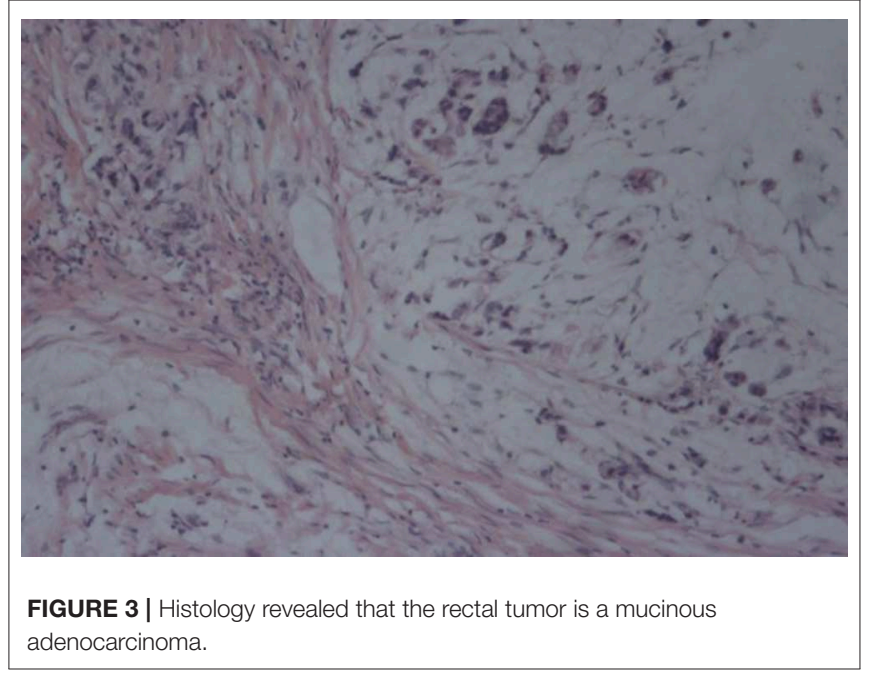

disorder (such as a rectal tumor secreting mucus that formed mucinous cysts or as retrorectal malignant tumors invading the rectum). Without a definite diagnosis, management was unclear. Because of the intestinal obstruction, however, and with the patient's consent, an abdominoperineal resection was performed. The postoperative pathology indicated that a rectal mucinous adenocarcinoma had invaded retrorectal dermoid cysts (Figure 3). The patient recovered well and, 1 month after the procedure, chemotherapy with the Xelox regimen (capecitabine and oxaliplatin) was initiated. He is now, 3 months later, being followed up. 


\section{DISCUSSION}

Rectal adenocarcinoma is the most common malignant tumor of the rectum; other rectal tumors include squamous carcinomas, neuroendocrine tumors, stromal tumors, and lymphomas (4-7). These rectal tumors have various clinical and pathological features, including histology, biological behavior, and prognosis, requiring different management. Their treatment depends on a precise diagnosis and classification. For advanced rectal adenocarcinomas, neoadjuvant chemoradiotherapy is recommended before surgery (8-10). For tumors not sensitive to chemoradiotherapy, surgery is the first choice. For rectal lymphomas, chemotherapy without surgery can be considered (6-11).

Colorectal mucinous adenocarcinoma, a subtype of colorectal adenocarcinoma, accounts for 6-20\% of all colorectal adenocarcinomas. The management of colorectal mucinous adenocarcinomas is not different from that of colorectal adenocarcinomas. Advanced mucinous adenocarcinoma, however, has a worse prognosis compared with non-mucinous adenocarcinoma $(12,13)$. Retrorectal dermoid cyst is a congenital disease, in the category of development cysts, which usually are benign but with a potential for malignant degeneration. About $30 \%$ of dermoid cysts are complicated by infection. Once the diagnosis of dermoid cysts has been made, surgical removal is indicated $(3,14,15)$. For cases of dermoid cysts along with an adenocarcinoma, surgical

\section{REFERENCES}

1. Bray F, Ferlay J, Soerjomataram I, Siegel RL, Torre LA, Jemal A. Global cancer statistics 2018: GLOBOCAN estimates of incidence and mortality worldwide for 36 cancers in 185 countries. CA Cancer J Clin. (2018) 68:394-424. doi: $10.3322 /$ caac. 21492

2. Arnold M, Sierra MS, Laversanne M, Soerjomataram I, Jemal A, Bray F. Global patterns and trends in colorectal cancer incidence and mortality. Gut. (2017) 66:683-91. doi: 10.1136/gutjnl-2015-30912

3. Baek SK, Hwang GS, Vinci A, Jafari MD, Jafari F, Moghadamyeghaneh Z, et al. Retrorectal tumors: a comprehensive literature review. World J Surg. (2016) 40:2001-15. doi: 10.1007/s00268-016-3501-6

4. Ngo N, Edriss H, Figueroa JA, Nugent K. Squamous cell carcinoma of the sigmoid colon presenting with severe hypercalcemia. Clin Colorectal Cancer. (2014) 13:251-4. doi: 10.1016/j.clcc.2014.06.006

5. Jung YS, Yun KE, Chang Y, Ryu S, Park JH, Kim HJ, et al. Risk factors associated with rectal neuroendocrine tumors: a crosssectional study. Cancer Epidemiol Biomarkers Prev. (2014) 23:1406-13. doi: 10.1158/1055-9965.EPI-14-0132

6. Singla R, Kumar P, Bahl A, Kumar S, Saran RK, Kar P. A case of primary rectal non-Hodgkin's lymphoma treated with chemotherapy. Trop Gastroenterol. (2008) 29:227-8.

7. Miettinen M, Lasota J. Gastrointestinal stromal tumors - definition, clinical, histological, immunohistochemical, and molecular genetic features and differential diagnosis. Virchows Arch. (2001) 438:1-12. doi: $10.1007 / \mathrm{s} 004280000338$

8. Glynne-Jones R, Wyrwicz L, Tiret E, Brown G, Rödel C, Cervantes A, et al. Rectal cancer: ESMO Clinical Practice Guidelines for diagnosis, treatment and follow-up. Ann Oncol. (2017) 28:iv22-40. doi: 10.1093/annonc/mdx224

9. Watanabe T, Muro K, Ajioka Y, Hashiguchi Y, Ito Y, Saito Y, et al. Japanese Society for Cancer of the Colon and Rectum (JSCCR) guidelines 2016 for the treatment of colorectal cancer. Int J Clin Oncol. (2018) 23:1-34. doi: 10.1007/s10147-017-1101-6 removal of the cysts, and the adenocarcinoma may be the best treatment strategy.

\section{CONCLUSION}

Malignancies have infiltrating potential, which means they can invade adjacent normal organs or tissues. This case presented a rectal mucinous adenocarcinoma invading into retrorectal dermoid cysts, indicating that malignancies can invade adjacent tumors, making their diagnosis and management complicated. In such cases, double primary tumors should be considered, and they should be removed surgically.

\section{ETHICS STATEMENT}

Written informed consent was obtained from the participant for the publication of this case report.

\section{AUTHOR CONTRIBUTIONS}

ZY conceived and revised the manuscript. RW designed and wrote the manuscript.

\section{FUNDING}

This research did not receive any specific grant from funding agencies in the public, commercial, or not-for-profit sectors.

10. Benson AB III, Venook AP, Al-Hawary MM, Cederquist L, Chen YJ, Ciombor KK, et al. Rectal Cancer, version 2.2018, NCCN clinical practice guidelines in oncology. J Natl Compr Canc Netw. (2018) 16:874-901. doi: $10.6004 /$ jnccn.2018.0061

11. Ismaili N, Bensouda Y, Mellas N, Errihani H. Role of chemotherapy in the management of primary rectal lymphoma: a case report and review of the literature. Cases J. (2009) 2:9373. doi: 10.1186/1757-16262-9373

12. Hugen N, Brown G, Glynne-Jones R, de Wilt JHW, Nagtegaal ID. Advances in the care of patients with mucinous colorectal cancer. Nat Rev Clin Oncol. (2015) 13:361-9. doi: 10.1038/nrclinonc.2015.140

13. Numata $M$, Shiozawa $M$, Watanabe $T$, Tamagawa $H$, Yamamoto $N$, Morinaga S, et al. The clinicopathological features of colorectal mucinous adenocarcinoma and a therapeutic strategy for the disease. World J Surg Oncol. (2012) 10:109. doi: 10.1186/1477-7819-10-109

14. Hobson KG, Ghaemmaghami V, Roe JP, Goodnight JE, Khatri VP. Tumors of the retrorectal space. Dis Colon Rectum. (2005) 48:1964-74. doi: 10.1007/s10350-005-0122-9

15. Munteanu I, Badulescu A, Mastalier B, Munteanu ML, Diaconu E, Popescu C. Retrorectal dermoid cyst: a rare clinical entity. Curr Health Sci J. (2013) 39:179-83.

Conflict of Interest: The authors declare that the research was conducted in the absence of any commercial or financial relationships that could be construed as a potential conflict of interest.

Copyright (C) 2019 Wang and Yan. This is an open-access article distributed under the terms of the Creative Commons Attribution License (CC BY). The use, distribution or reproduction in other forums is permitted, provided the original author(s) and the copyright owner(s) are credited and that the original publication in this journal is cited, in accordance with accepted academic practice. No use, distribution or reproduction is permitted which does not comply with these terms. 